\title{
Beauveria brongniartii - a potential biocontrol agent for use against manuka beetle larvae damaging dairy pastures on Cape Foulwind
}

\author{
R.J. Townsend, T.L. Nelson and T.A. Jackson \\ AgResearch, Lincoln Research Centre, Private Bag 4749, Christchurch 8140, New Zealand \\ Corresponding author: richard.townsend@agresearch.co.nz
}

\begin{abstract}
Manuka beetles (Pyronota sp.; Scarabaeidae) are serious and persistent pests of dairy pastures on Cape Foulwind, Westport. When a selection of scarab-active fungal isolates were tested against $3^{\text {rd }}$ instar larvae of two Pyronota species, a locally sourced Beauveria brongniartii (F636) isolate consistently achieved the fastest and highest levels of larval mortality. Topical application of F636 caused an average of $80 \%$ larval mortality 6 weeks post-treatment. Mortality was shown to be dose rate dependent for both Pyronota species. When treatments were applied by incorporating rice grains colonised by the fungus into soil, simulating field application, F636 again produced the fastest and highest levels of larval mortalities, averaging 70\% 6 weeks post-application. Mortalities of both Pyronota species reached $100 \%$ after 8 weeks when the assay medium was a grey sand based soil (ex Cape Foulwind). Isolate F636 shows promise as a biological control agent for this pest and field trials have been carried out in the autumn of 2010 .
\end{abstract}

Keywords Beauveria brongniartii, Pyronotafestiva, Pyronota setosa, manuka beetle, biocontrol agent.

\section{INTRODUCTION}

Pyronota spp. (Coleoptera: Scarabaeidae), commonly called manuka beetle, are related to the New Zealand grass grub, Costelytra zealandica (White), which is a major pasture pest on lighter soils throughout New Zealand. Manuka beetle larvae have been reported to cause pasture damage in several regions of New Zealand (Thomson et al. 1978; Miln et al. 1983; Chapman 1984), often associated with grass grub damage in areas close to bush margins (Thomson et al. 1979). Following large scale pasture developments on the West Coast ("hump and hollow", "flipping"), insect pests have caused significant decreases in pasture yield and losses of sown pasture species. In recent years high populations of manuka beetles have become the dominant pests causing significant pasture production losses during autumn and winter on dairy farms on Cape Foulwind.

Two Pyronota species have been identified from the damaged pastures $-P$. festiva and P. setosa (det. Shaun Forgie, Manaaki Whenua Landcare Research). Pathogen surveys of these manuka beetle populations by AgResearch have shown low infection rates by bacteria and protozoans but have recorded moderate levels of infection in $3^{\text {rd }}$ instar larvae by the Deuteromycete fungi, 
Metarhizium and Beauveria. Isolates of both of these fungi have been used as biocontrol agents against scarab pests (Glare et al. 1994; Kessler et al. 2003). One isolate of B. brongniartii (Saccardo) Petch has been highlighted as a potential biocontrol agent for use against manuka beetle larvae (Townsend \& Jackson 2008).

This paper reports on a series of bioassays carried out to examine the efficacy of $B$. brongniartii F636 as an entomopathogen of manuka beetle larvae compared to several other known scarab-active fungal isolates.

\section{METHODS}

\section{Insects and fungal strains}

Third instar larva of both Pyronota festiva (F.) and Pyronota setosa (Given) were collected from damaged pastures on Landcorp Farming Ltd properties on Cape Foulwind during autumn and winter of 2009 and held at $4^{\circ} \mathrm{C}$ until required. The average weight of $P$. festiva larvae was $0.077 \mathrm{~g}$, while $P$ setosa was $0.051 \mathrm{~g}$. Two fungal isolates from the AgResearch reference collection, Metarhizium anisopliae (F605) and Beauveria bassiana (F227), plus M. anisopliae (DAT-F001, Chaferguard $^{\mathrm{TM}}$ ), were selected for their known scarab activity to compare against a B. brongniartii (F636) isolated from cadavers of Pyronota larvae collected from Cape Foulwind pastures in May 2007. The worst performing of these isolates, F227, was replaced in the final bioassay with a strain of B. brongniartii (F156) known to have caused an epizootic in grass grub larvae in the Waikato in 1993.

The fungal strains were tested in a series of bioassays against both species of manuka beetle larvae to determine infectivity and time to death among the treated larvae over a range of experimental conditions. For Bioassays 1,2 and 3, suspensions of the fungi were prepared by suspending conidia from 14 day old PDA cultures in $0.01 \%$ Triton X-100. The spore concentration was estimated using a haemocytometer (improved Neubauer, $0.1 \mathrm{~mm}$ depth) and adjusted to a final concentration of $5 \times 10^{7}$ conidia $/ \mathrm{ml}$. For Bioassay 4 , conidia were produced via solid substrate production (rice) to achieve a loading of approximately $10^{8}$ conidia/g of rice. All four bioassays were kept in the dark in controlled temperature cabinets at $15^{\circ} \mathrm{C}$ for the duration of the trials.

\section{Bioassay 1: Preliminary testing}

Twelve healthy feeding $3^{\text {rd }}$ instar larvae were each treated with a dose of $10 \mu \mathrm{l}$ of fungal suspension containing $5 \times 10^{7}$ viable conidia for each treatment (DAT-F001, F227, F636 and F605). The inoculum was applied topically on the underside of the larva using a pipette. The control larvae were treated with a $10 \mu \mathrm{l}$ droplet of tap water. Treated larvae were kept individually in tissue culture trays for $24 \mathrm{~h}$ then placed into $35 \mathrm{ml}$ tubes containing 22-25 g of sieved Wakanui silt loam soil at $17-20 \%$ soil moisture. Each tube had a $5 \mathrm{~mm}$ cube of carrot placed on the soil surface as a food source for the manuka beetle larva. The carrot cubes were replaced at each assessment. Assessments began 3 weeks post-treatment when each larva was removed from its tube and assessed as healthy, moribund or dead then replaced in the same tube. Weekly assessments continued until 7 weeks post-treatment.

\section{Bioassay 2: Stage of development}

The same fungal treatments and procedures were used as in Bioassay 1 and applied to twelve healthy feeding $3^{\text {rd }}$ instar and twelve 'mature' (fully fed) $3^{\text {rd }}$ instar larvae of both species. The control larvae were treated with a $10 \mu$ d droplet of tap water. The same assessment regime was followed.

\section{Bioassay 3: Spore dosage}

In this assay, twelve healthy feeding $3^{\text {rd }}$ instar larvae of each Pyronota species were treated with topically applied $10 \mu \mathrm{l}$ doses containing $0,5 \times$ $10^{3}, 5 \times 10^{5}$ and $5 \times 10^{7}$ conidia of $B$. brongniartii (F636). The control larvae were treated with a 10 $\mu \mathrm{l}$ droplet of tap water. Again the same procedures and assessment regime was followed.

\section{Bioassay 4: In-soil test}

Twelve healthy, feeding $3^{\text {rd }}$ instar $P$. festiva and $P$. setosa larvae were placed individually into 120 
$\mathrm{ml}$ clear plastic tubes containing $75 \mathrm{~g}$ of either the grey sand soil typical of most damage-prone pastures on Cape Foulwind or Wakanui silt loam typical of a grass grub-prone area in Canterbury. Both soils were at approximately $20 \%$ soil moisture. For each treatment one conidia-covered rice grain was placed in each tube, equivalent to approximately $7.2 \times 10^{14}$ spores/ha. Tubes in the control treatment had one non-fungus-infected rice grain placed in the soil. Other procedures were the same as used in previous assays except this assay was assessed 4, 6 and 8 weeks posttreatment.

\section{Statistical analysis}

The full percentage mortality data set from all four bioassays was statistically analysed using the Log-Rank test. The Log-Rank test compares the time-varying mortalities of any two treatment groups over the trial period and assesses the level of significance of the difference between the groups.

\section{RESULTS}

The tables below record the percentage mortality to $3^{\text {rd }}$ instar larvae of $P$ festiva and $P$ setosa caused by the fungal isolate treatments applied directly (topical application) or indirectly (as conidia on rice into soil). Analysis of the full data set (not presented) showed that, in general, both species and both stages of $3^{\text {rd }}$ instar larvae exhibited equal susceptibility to the strains of fungi used in the bioassays. Thus, in the tables below, mean mortalities for the two manuka beetle species and for different stages of $3^{\text {rd }}$ instar larvae, where tested, are reported in an overall analysis for each bioassay.

When fungal conidia were applied topically to larvae in Bioassay 1 the fastest and highest mortality rates were caused by treatment with $B$. brongniartii F636, which killed all larvae within 5 weeks of treatment and caused significantly $(\mathrm{P}<0.05)$ higher mortality to larvae than all other fungal treatments in Bioassay 1 (Table 1).

In Bioassay 2 mortality due to the various fungi treatments did not differ significantly $(\mathrm{P}<0.05)$ between the two manuka beetle species, and therefore the data were pooled. Overall mortalities were lower than in the first bioassay but the highest mortalities followed treatment with B. brongniartii F636 $(\mathrm{P}<0.05)$ (Table 2). This strain again caused significant early mortality, reaching more than $50 \%$ by 6 weeks from treatment. Two exceptions (data not shown) to this overall result were feeding stage $P$. setosa larvae treated with F605 and mature stage $P$. setosa treated with F227, which both had mortality rates not significantly different to the same P. setosa life stages treated with F636.

In Bioassay 3 (Table 3 ) mortality due to dose rate did not differ significantly $(\mathrm{P}<0.05)$ between the two manuka beetle species, and therefore the data were pooled. When larvae were treated with varying doses of $B$. brongniartii F636, the highest dose of $10^{5}$ conidia/larva produced mortality similar to that seen in the previous experiments reaching $83 \%$ after 7 weeks. This was significantly $(\mathrm{P}<0.01)$ greater than the mortality caused by treatment with $10^{3}$ conidia per larva, which only reached $38 \%$ by 7 weeks post-treatment. Mortality due to both the higher rates was significantly $(\mathrm{P}<0.01)$ greater than the $10^{1}$ rate and control treatment mortalities, which were not significantly different from each other.

Excessively high levels of Pyronota larval mortality in the Wakanui soil control treatments in Bioassay 4 meant that no valid comparisons could be made between the various fungal isolates tested in this soil. Table 4 shows control mortality was higher in the grey sand soil than in previous experiments but, once again, $B$ brongniartii F636 caused significantly $(\mathrm{P}<0.05)$ faster and higher mortality rates than the other fungal treatments or control reaching $100 \%$ death by 12 weeks post-treatment.

\section{DISCUSSION}

The common manuka beetle $P$. festiva has often been reported as a minor pasture pest but the uncommon $P$. setosa has been either unrecognised or unrecorded as causing even minor pasture damage. As $P$. setosa comprise up to half of the manuka beetle numbers in some of the most damaged pastures on Cape Foulwind it 
Table 1 Mortality (\%) of manuka beetle larvae (mean for both species combined) caused by topical application of four strains of selected entomopathogenic fungi in Bioassay 1.

\begin{tabular}{lcccccc}
\hline Treatments & & 3 weeks & 4 weeks & 5 weeks & 6 weeks & 7 weeks \\
\hline Control & $\mathrm{a}^{1}$ & 8 & 8 & 13 & 13 & 13 \\
DAT-F001 & $\mathrm{bc}$ & 25 & 33 & 42 & 42 & 46 \\
F227 & $\mathrm{ab}$ & 21 & 21 & 21 & 29 & 29 \\
F605 & $\mathrm{c}$ & 25 & 34 & 54 & 63 & 67 \\
F636 & $\mathrm{d}$ & 67 & 96 & 100 & 100 & 100 \\
\hline
\end{tabular}

${ }^{1}$ Treatments with no letter in common are significantly different $(\mathrm{P}<0.05)$.

Table 2 Mortality (\%) of manuka beetle larvae (mean for species and life stages combined) caused by topical application of four strains of selected entomopathogenic fungi in Bioassay 2.

\begin{tabular}{lcccccc}
\hline Treatments & & 3 weeks & 4 weeks & 5 weeks & 6 weeks & 7 weeks \\
\hline Control & $\mathrm{ab}^{1}$ & 2 & 2 & 4 & 9 & 11 \\
DAT-F001 & $\mathrm{acd}$ & 0 & 0 & 7 & 15 & 25 \\
F227 & $\mathrm{bce}$ & 4 & 4 & 11 & 17 & 19 \\
F605 & $\mathrm{de}$ & 9 & 11 & 11 & 17 & 36 \\
F636 & $\mathrm{f}$ & 32 & 42 & 48 & 58 & 71 \\
\hline
\end{tabular}

${ }^{1}$ Treatments with no letter in common are significantly different $(\mathrm{P}<0.05)$.

Table 3 Mortality (\%) of manuka beetle larvae (mean for species combined) treated with four rates of topically applied B. brongniartii F636 in Bioassay 3.

\begin{tabular}{lcccccc}
\hline Treatments & & 3 weeks & 4 weeks & 5 weeks & 6 weeks & 7 weeks \\
\hline Control & $\mathrm{a}^{1}$ & 0 & 0 & 0 & 0 & 0 \\
$10^{1}$ spores & $\mathrm{a}$ & 4 & 4 & 4 & 4 & 4 \\
$10^{3}$ spores & $\mathrm{b}$ & 4 & 4 & 13 & 25 & 38 \\
$10^{5}$ spores & $\mathrm{c}$ & 42 & 58 & 63 & 75 & 83 \\
\hline
\end{tabular}

${ }^{1}$ Treatments with no letter in common are significantly different $(\mathrm{P}<0.05)$.

is important that any potential biocontrol agent is equally effective against both species. The bioassays reported in this paper have revealed that both species are susceptible to infection by a range of entomopathogenic fungi with similar effects on both species. Interestingly, strains of Metarhizium and Beauveria isolated from scarab hosts collected elsewhere in New Zealand or overseas did not have as much effect as the local strain, B brongniartii F636, isolated from Pyronota larvae collected from Cape Foulwind pastures.
The results suggest that species specificity may be more important than wider adaptation to the Family Scarabaeidae. This is all the more interesting as few naturally fungus-infected larvae have been recovered from the Pyronota infested pastures (R.J. Townsend, personal observations).

Beauveria brongniartii F636 is clearly the best biocontrol candidate, as it consistently caused the fastest mortality and the highest total mortality in all bioassays. It also appeared to be effective against feeding and late stage $3^{\text {rd }}$ instar larvae. 
Table 4 Mortality (\%) of manuka beetle larvae (mean for species combined) in grey sand soil caused by four fungal isolates applied as conidia grown on rice in Bioassay 4.

\begin{tabular}{llccc}
\hline Treatments & & $\begin{array}{c}4 \\
\text { weeks }\end{array}$ & $\begin{array}{c}6 \\
\text { weeks }\end{array}$ & $\begin{array}{c}8 \\
\text { weeks }\end{array}$ \\
\hline Control & abc $^{1}$ & 13 & 29 & 46 \\
DAT-F001 & ade & 0 & 29 & 54 \\
F156 & bdf & 17 & 33 & 54 \\
F605 & cef & 13 & 33 & 58 \\
F636 & g & 38 & 83 & 100 \\
\hline
\end{tabular}

${ }^{1}$ Treatments with no letter in common are significantly different $(\mathrm{P}<0.05)$.

This is of practical importance as observations in the field have shown that development of manuka beetle larvae can be very variable with some becoming fully fed or 'mature' by early May while others do not complete their growth until as late as October. The 'mature' 3rd instar larvae have fully developed fat bodies and are not as active as feeding $3^{\text {rd }}$ instar larvae. Both the feeding and mature $3^{\text {rd }}$ instar larvae were shown to be equally susceptible to topically applied $B$. brongniartii F636. This is an important finding as it indicates that B. brongniartii F636 could be effective in both autumn, when most larvae are still in the feeding phase, and spring, when soil temperatures rise and a large proportion of the manuka beetle larvae will already be 'mature'.

Larval dose rate testing with F636 showed a significant increase in the speed with which mortality occurred and in the total percentage mortality as the dose rate increased. This suggests that a granular formulation, which applies concentrated doses of conidia, may be an effective field application strategy to establish fungal disease within a manuka beetle population. The results of Bioassay 4 support this hypothesis by showing that B. brongniartii F636, applied as conidia on rice, caused extremely high mortalities of manuka beetle larvae in the grey sand 'flipped' soil type commonly found under badly damaged pastures on Cape Foulwind. A field trial using two different formulations of $B$. brongniartii $\mathrm{F} 636$ has been established in autumn 2010 to test the efficacy of B. brongniartii F636 under field conditions.

\section{ACKNOWLEDGEMENTS}

We sincerely thank Chikako van Koten for the statistical analysis and Ben Giquel for technical assistance with the bioassays. This research has been supported by Landcorp Farming Ltd and The New Zealand Foundation for Research, Science and Technology (Contract LINX0804).

\section{REFERENCES}

Chapman RB 1984. Pasture pests. In: Scott RR ed. New Zealand pest and beneficial insects. The Caxton Press, Christchurch, New Zealand. Pp. 119-142.

Glare TR, Townsend RJ, Young SD 1994. Temperature limitations on field effectiveness of Metarhizium anisopliae against Costelytra zealandica(White)(Coleoptera:Scarabaeidae) in Canterbury. Proceedings of the 47th New Zealand Plant Protection Conference: 266270.

Kessler P, Matzke H, Keller S 2003. The effect of application time and soil factors on the occurrence of Beauveria brongniartii applied as a biological control agent in soil. Journal of Invertebrate Pathology 84(1): 15-23.

Miln AJ, Carpenter A, Bates LH 1983. Insecticidal control of manuka beetle. Proceedings of the $36^{\text {th }}$ New Zealand Weed and Pest Control Conference: 203-206.

Thomson NA, Rys G, Carpenter A 1978. Control of manuka beetle. Proceedings of the $31^{\text {st }} \mathrm{New}$ Zealand Weed and Pest Control Conference: 164-166.

Thomson NA, Miln AJ, Kain WM 1979. Biology of manuka beetle in Taranaki. Proceedings of the $32^{\text {nd }}$ New Zealand Weed and Pest Control Conference: 80-85.

Townsend RJ, Jackson TA 2008. Biocontrol - a possible option to control manuka beetle (Pyronota spp.) causing pasture damage on dairy farms on the West Coast. New Zealand Plant Protection 61: 388 (Abstract only). 